\title{
Posterior Restoration Selection Among General Dental Practices in Malaysia: A Preliminary Study
}

\author{
Abdul Azim Asy Abdul Aziz', Aimi Amalina Ahmad', Azlan Jaafar ${ }^{2}$, Norazlina Mohammad ${ }^{1}$, Aws H Ali Al- \\ Kadhim $^{1}$ \\ ${ }^{1}$ Department of Conservative and Prosthodontics, Faculty of Dentistry, USIM. \\ ${ }^{2}$ Department of Periodontology \& Community Oral Health, Faculty of Dentistry, USIM.
}

\begin{abstract}
Introduction: Tooth restoration is a common, routine procedure among dentists but still has its own difficulties especially for posterior teeth. As it is a straightforward procedure, some dentists are not aware of the difficulties that may contribute in reducing the longevity of the filling. The aim of the study is to determine the difficulties encountered during and after placement of restorative materials in deep cavities. Materials and methods: Standardized questionnaires were divided randomly among general private dental practitioners in Kuala Lumpur. Chi-square test was used to determine any significant factors associated with difficulties of material placement. Results: This study showed that the most frequent difficulties encountered among practitioners were to obtain good moisture control (39.0\%). No significant association was found between obtaining good moisture control and year of clinical experience $(p=0.286)$ and also place of graduation with the manipulation of the materials $(p=0.542)$. Conclusion: Dental practitioners claimed that it was difficult to obtain good moisture control in placement of posterior restoration. Thus, it is an obligation of dental practitioners to practice proper isolation and good manipulation of materials on posterior restoration.
\end{abstract}

KEYWORDS: Posterior Restoration, Selection, General Dental Practices, Malaysia.

\section{INTRODUCTION}

Posterior restoration or dental filling is a treatment to restore the function, integrity and morphology of a missing tooth structure of the back teeth, starting from the first premolar up to the third molar. Commonly, the molar region will exhibit forces from $597 \mathrm{~N}$ to $847 \mathrm{~N}$, especially during biting or chewing that make the filling materials selection very crucial for this region. ${ }^{1}$ Basically, filling materials for posterior dentition are divided into two; non-tooth coloured restoration like amalgam, gold and tooth coloured restoration, such as composite and glass ionomer cement (GIC). Amalgam has been the gold standard in permanent restoration for many

Corresponding Author:

Dr. Aws Hashim Ali Al-Kadhim Universiti Sains Islam Malaysia, Level 15, Menara B, Persiaran MPAJ, Jalan Pandan Utama, Pandan Indah, 55100 Ampang, Kuala Lumpur.

Tel No : +60342892400 (ext. 2430)

Email : awshashim@usim.edu.my decades as it has superior durability as compared to the others, despite its non-aesthetical factor. It is less moisture sensitive but requires the removal of sound tooth structure to facilitate its retention. ${ }^{2}$ Therefore, amalgam is slowly replaced by tooth coloured restoration and other biocompatible restorations.

Previously, composite was recommended to be used for (G.V Blacks classification) Class I, Class III and Class IV, whereby there is less occlusal stress. However, the use of composite resin restorations has significantly increased over the years due to technology advancement that has improved its physical and mechanical properties. Composite does not only preserve the tooth structure during cavity preparation but also provides natural-looking restorations. ${ }^{3}$ Continuous research has resulted in the formulation and introduction of a new generation of dentin bonding agents that have increased the adhesion of resin to tooth structure. As a result, composite resin became more popular among the general dental practices. Despite their general 
acceptance, composite resin is still presented with drawbacks, including marginal discolouration, shrinkage, micro leakage that will eventually lead to secondary caries and moisture sensitive, especially for posterior restorations. ${ }^{4}$

Alongside with the development of resin based restoration (composite) is the introduction of glass ionomer cement (GIC) by Wilson \& Kent in 1969. GIC has been evolved for many decades until the innovation successfully produced the Resin Modified Glass lonomer Cement (RMGIC). A study revealed that generally RMGIC have a much higher flexural strength as compared to the conventional GIC, approximately $71 \mathrm{MPa}$ vs $11 \mathrm{MPa} .{ }^{4}$ It was found that in RMGIC, secondary caries was not detected after 3 years of restoration. ${ }^{5}$ However, in a three-year study by Sharo K, in 2010, the contours and surface texture of RMGIC were found to be the poorest as compared to composite resin and compomer.

Placement of the posterior restoration can be a great challenge to the dentist due to several faced obstacles, such as pool of saliva and limited accessibility. Selection of posterior restoration needs to be carefully and effectively done since it will directly affect restoration longevity and treatment success rate. $^{6}$ Posterior restoration failures are associated with a few conditions, including marginal defects, secondary caries, and discolorations. ${ }^{6,7}$ These failures might be caused by poor material selection as well as improper handling and manipulation of filling placement, such as poor marginal adaptation, poor proximal contact, incorporation of air or debris into the restoration and ineffective moisture control. ${ }^{8}$ Therefore, the operator must be able to identify a suitable restorative material prior to placement of the restorations at posterior sites, to ensure a sustainable restoration for a prolonged treatment success.

According to Demarco et al., (2011), ${ }^{9}$ during the restorative procedure, the patient, operator and dental material are the main predictors of a long survival rate of posterior restoration. The operator must be equipped with current knowledge and is updated with the development of dental materials. The selection of dental materials may also be influenced by the patient's request for certain types of restorative material, which could be mainly for aesthetic reasons. Apart from these factors, the site and size of cavity are also an important consideration because it will also affect the manipulation of material as well as its strength and longevity. The trend towards tooth coloured restoration is increasing, especially in developed countries like US, UK, Japan and Norway. It is reported in Norway that only $3 \%-7 \%$ of restorations in permanent teeth were found to be of amalgam in 2002. ${ }^{10}$ In contrast, in developing countries like Myanmar and Kuwait, ${ }^{10}$ half of the restorations that were placed were composite and half were amalgam. Even though the trend towards the use of tooth coloured restorations for posterior sites is increasing in Malaysia, the data is not yet documented.

Thus, this research aims to assess the preference for tooth coloured restoration among Malaysian dentists. The hypothesis to be tested is the increasing trend in the use of tooth coloured restoration on posterior teeth among general dental practices and it is a null hypothesis.

\section{MATERIAL AND METHODS}

This study is an extension of a study conducted by Abdul Aziz et al., 2018 among private dental practitioners in Kuala Lumpur. A self-administered questionnaire with modification was distributed among 239 dental practitioners who attended a twoday dental health seminar ${ }^{12}$. The seminar was held at the Faculty of Dentistry, Universiti Sains Islam Malaysia (USIM), in Kuala Lumpur. Any dental specialist, students or allied health that attended the seminar were excluded from participating in the study.

This study was granted an ethical approval from the faculty research committee and has obtained approval from the participants before the study commencement. Data analysis was performed by using SPSS Version 21.0. A descriptive analysis was done to exhibit the frequency and mean. Further analysis that looked into the association and correlation of data was done using Chi-square and Spearman's correlation coefficient.

\section{RESULTS}

A total of 198 questionnaires, $82.8 \%$ of response rate, were reinstated from the participants. The mean age of respondents was 32 years $(S D=8.14)$. 
The majority of them were local graduates (66.7\%) and are practising dentistry within five years (68.2\%). The percentage according to gender was $67.2 \%$ of females and $32.8 \%$ of male local graduates. The summary characteristics of respondents are shown in Table 1.

Table 1: Summary characteristics of respondent

\begin{tabular}{ccc}
\hline Variables & Mean (SD) & $\begin{array}{l}\text { Frequency } \\
\text { (\%) }\end{array}$ \\
\hline Age (Years) & $31.5(8.14)$ & $151(79.1)$ \\
25 to 34 & & $22(11.5)$ \\
35 to 44 & $13(6.8)$ \\
45 to 54 & $5(2.6)$ \\
$\geq 55$ & \\
Sex & $65(32.8)$ \\
Male & $133(67.2)$ \\
Female & \\
Graduate & $132(66.7)$ \\
Local & $66(33.3)$ \\
Oversea & \\
Duration of & practice & \\
(years) & & $135(68.2)$ \\
0 to 5 & $22(11.1)$ \\
6 to 10 & $13(6.6)$ \\
11 to 15 & $28(14.1)$ \\
$>15$ &
\end{tabular}

Figure 1 depicts types of material use for posterior tooth, depending on the depth of tooth cavity. Composite was the most preferable restoration for overall (56.3\%), shallow (86.3\%) and moderate (56.6\%) cavity. However, the majority of respondent preferred to use amalgam for deep cavity restoration $(36.0 \%)$ as compared to composites (33.0\%).

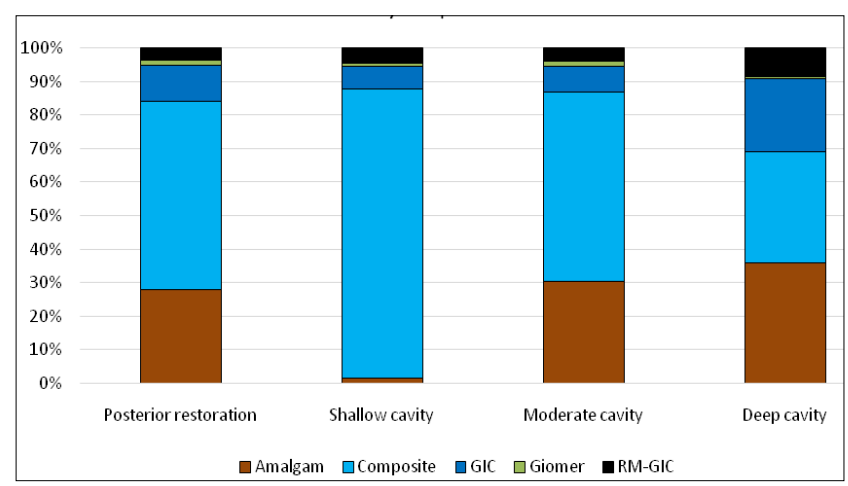

Figure 1: Type of restoration material use for posterior tooth by respondent

Table 2 depicts factors that influence the choice of materials among respondents. Respondents agreed that most of the listed factors have influence their choices for posterior restoration, except for the dentist's concern with mercury toxicity. The majority of them disagreed $(52.0 \%)$ that it influenced their choice.
Table 3 denotes a significant association between types of material used for deep cavity and gender $\left[\mathrm{x}^{2}=6.559, \mathrm{df}=2, p=0.038\right]$. In Table 4 , a significant correlation was found between duration of practising dentistry with patient's concern with mercury toxicity $(p=0.016)$ and the feasibility to obtain moisture control $(p=0.024)$.

\section{DISCUSSION}

The results of this study shows that the use of the amalgam increases with the deeper cavities, and it also confirmed that tooth coloured materials, especially composite, has been the dominant preference among general dental practices in Malaysia $(72.1 \%)$. On the other hand, the use of amalgam has not been completely abandoned as shown in Figure 1.

A similar finding was found among Pakistani dentists, whereby $81.5 \%$ of the dentists chose the same preference ${ }^{11}$. This current trend follows the universal pattern in some developed countries like Norway, Finland and United Kingdom, as reported by WHO in $2009^{12}$. This indicated that, the Malaysian practitioners seem to be at par and are following the current trend of developed countries.

In this study, the use of amalgam increases with deeper cavities. However, the number does not supersede the tooth coloured restoration. From this study another finding on the increased use of GIC in deep cavity, as shown in Figure 1 , is alarming. Hickel et al. ${ }^{13}$ reported that, $1.9 \%-14.4 \%$ of GIC has median annual failure rate, which is the highest among amalgam and composite restoration. GIC restorations exhibit wear three times higher than composite resins and five times higher than amalgam. ${ }^{14}$ Because of the above disadvantages, GIC should not be used to restore the occlusal surfaces of posterior teeth.

In order to obtain good retention and resistance form for amalgam filling, the removal of sound tooth structures maybe required. The increase in awareness towards minimum interventional dentistry and preservation of tooth structure ${ }^{11}$ may have encouraged $97.0 \%$ of dentists in this study to opt for resin-bonded and chemical-bonded materials, as shown in Table 2. 
Table 2: Factor influencing choice of restoration materials $(\mathrm{N}=198)$

\begin{tabular}{|c|c|c|c|c|c|}
\hline \multirow[b]{2}{*}{ Factors } & \multicolumn{5}{|c|}{ Frequency (\%) } \\
\hline & $\begin{array}{l}\text { Strongly } \\
\text { Agree }\end{array}$ & Agree & Don't know & Disagree & Strongly Disagree \\
\hline Preservation of tooth structure. & $103(52.3)$ & $88(44.7)$ & $1(0.5)$ & $3(1.5)$ & $2(1.0)$ \\
\hline $\begin{array}{l}\text { Patients concern regarding the } \\
\text { mercury toxicity. }\end{array}$ & $18(9.3)$ & $82(42.3)$ & $17(8.8)$ & $67(34.5)$ & $10(5.2)$ \\
\hline Ease of handling. & $78(39.6)$ & $108(54.8)$ & $1(0.5)$ & $8(4.1)$ & $2(1.0)$ \\
\hline $\begin{array}{l}\text { Documented clinical perfor- } \\
\text { mance of the material. }\end{array}$ & $76(38.8)$ & $108(55.1)$ & $10(5.1)$ & $1(0.5)$ & $1(0.5)$ \\
\hline $\begin{array}{l}\text { Feasibility to obtain moisture } \\
\text { control. }\end{array}$ & $123(62.8)$ & $66(33.7)$ & $0(0.0)$ & $6(3.1)$ & $1(0.5)$ \\
\hline Patient aesthetic demand. & $62(31.5)$ & $106(53.8)$ & $5(2.5)$ & $21(10.7)$ & $3(1.5)$ \\
\hline Patient financial situation. & $31(16.0)$ & $93(47.9)$ & $18(9.3)$ & $46(23.7)$ & $6(3.1)$ \\
\hline $\begin{array}{l}\text { Patient request for a certain } \\
\text { material. }\end{array}$ & $27(13.7)$ & $114(57.9)$ & $7(3.6)$ & $44(22.3)$ & $5(2.5)$ \\
\hline $\begin{array}{l}\text { Dentist concern regarding the } \\
\text { mercury toxicity. }\end{array}$ & $16(8.2)$ & $64(32.7)$ & $14(7.1)$ & $79(40.3)$ & $23(11.7)$ \\
\hline
\end{tabular}

The distribution of dentists by sex in Malaysia as reported by the Malaysian Dental Council (MDC) in 2010 is $37.6 \%$ (male): $62.4 \%$ (female). This ratio may affect the selection of posterior filling materials. As per this study, the relation between amalgam filling in deep cavity and female gender is significant, $(p=0.038)$. On the other hand, a study in United Kingdom revealed that, the composite usage for large posterior restorations is "always or often" reported among male dentists, $(p=0.03)^{15,16}$; thus showing that, gender too has an effect on the selection of posterior filling materials.

The study found that correlation between factor influencing choices of restoration materials (feasibility to obtain moisture control) with years of practice is significant with $p$ value of 0.024 . In contrast, the majority of young dentists prefer tooth colour restoration for posterior restoration. Composite is not recommended for a tooth that cannot be effectively isolated. This is a basic requirement or regulation that was stated by the American Dental Association Council. Mjor et al., $(2000)^{6}$ stated that good tooth isolation in placing posterior restoration will reduce secondary caries incidence and replacement rate, and it can be achieved by more competent and experienced dentists. Cotton roll isolation for posterior region is quite a challenge among younger dentists. Hence, it is recommended that they use rubber dam as a primary method of isolation, especially for posterior filling to ease in obtaining moisture control.
Table 3: The association between type of materials use for deep cavity and GDP profiles using chi-square analysis

\begin{tabular}{|c|c|c|c|c|}
\hline \multirow[b]{2}{*}{$\begin{array}{l}\text { Demo- } \\
\text { graphic } \\
\text { profile }\end{array}$} & \multicolumn{3}{|c|}{ Type of materials use } & \multirow{2}{*}{$\begin{array}{c}p- \\
\text { value }\end{array}$} \\
\hline & $\begin{array}{c}\text { Amalgam } \\
\text { n (\%) }\end{array}$ & $\begin{array}{c}\text { Composite- } \\
\text { based } \\
\text { n (\%) }\end{array}$ & $\begin{array}{c}\text { GIC- } \\
\text { based } \\
\text { n (\%) }\end{array}$ & \\
\hline \multicolumn{5}{|l|}{ Gender } \\
\hline Male & $\begin{array}{c}16 \\
(24.6)\end{array}$ & $\begin{array}{c}28 \\
(43.1)\end{array}$ & $\begin{array}{c}21 \\
(32.3)\end{array}$ & 0.038 \\
\hline Female & $\begin{array}{c}55 \\
(41.7)\end{array}$ & $\begin{array}{c}37 \\
(28.0)\end{array}$ & $\begin{array}{c}40 \\
(30.3)\end{array}$ & \\
\hline \multicolumn{5}{|l|}{ Graduate } \\
\hline Local & $\begin{array}{c}50 \\
(38.2)\end{array}$ & $\begin{array}{c}45 \\
(34.4)\end{array}$ & $\begin{array}{c}36 \\
(27.5)\end{array}$ & 0.326 \\
\hline Experience & $\begin{array}{c}21 \\
(31.8)\end{array}$ & $\begin{array}{c}20 \\
(30.3)\end{array}$ & $\begin{array}{c}25 \\
(37.9)\end{array}$ & \\
\hline$\leq 5$ years & $\begin{array}{c}56 \\
(41.5)\end{array}$ & $\begin{array}{c}42 \\
(31.1)\end{array}$ & $\begin{array}{c}37 \\
(27.4)\end{array}$ & 0.057 \\
\hline$>5$ years & $\begin{array}{c}15 \\
(24.2)\end{array}$ & $\begin{array}{c}23 \\
(37.1)\end{array}$ & $\begin{array}{c}24 \\
(38.7)\end{array}$ & \\
\hline
\end{tabular}

At present, there is still no recommendation from respective authority in Malaysia with regard to the influence of material selection in placing restoration, though some countries like United Kingdom and Finland already have these regulations in place. ${ }^{17,18}$ Tran and Messer in $2003^{19}$ mentioned that the trend towards tooth coloured restoration preference is also a reflection of the dental school teaching; thus, another research is recommended to relate the current findings with the teaching of permanent posterior restorations in Malaysian dental schools for undergraduates. On the other hand, the current research needs to be extended to a larger sample drawn from other regions or states in Malaysia and to include both government and 
private sectors dental practitioners to ensure a more representative result.

Table 4: Correlation between factor influencing choice of restoration materials with duration of practice using Spearman correlation $(n=198)$

\begin{tabular}{|c|c|c|}
\hline Factor influence & $\mathbf{R}_{\mathrm{s}}$ & $p$-value \\
\hline Preservation of tooth structure. & -0.049 & 0.492 \\
\hline $\begin{array}{l}\text { Patients concern regarding the } \\
\text { mercury toxicity. }\end{array}$ & -0.173 & 0.016 \\
\hline Ease of handling. & 0.004 & 0.952 \\
\hline $\begin{array}{l}\text { Documented clinical performance } \\
\text { of the material. }\end{array}$ & -0.033 & 0.646 \\
\hline $\begin{array}{l}\text { Feasibility to obtain moisture } \\
\text { control. }\end{array}$ & 0.162 & 0.024 \\
\hline Patient aesthetic demand. & 0.011 & 0.873 \\
\hline Patient financial situation. & -0.090 & 0.213 \\
\hline $\begin{array}{l}\text { Patient request for a certain } \\
\text { material. }\end{array}$ & -0.019 & 0.795 \\
\hline $\begin{array}{l}\text { Dentist concern regarding the } \\
\text { mercury toxicity. }\end{array}$ & -0.036 & 0.618 \\
\hline
\end{tabular}

\section{CONCLUSION}

Based on the given questionnaire, the general dental practices in Malaysia tend to choose tooth coloured restoration as their preferred choice for posterior permanent restorations. The hypothesis is accepted since most of them used composite more for the above mentioned purpose, and the major factor that leads to their choice is preservation of tooth structure.

\section{ACKNOWLEDGMENTS}

The authors thank the lecturers, dentists and research assistants involved in this study. Financial support was from Research Management Centre of USIM under the short term grant (PPP/USG-0216/ FPG/30/18316) and the programme fully support by the Faculty of Dentistry USIM.

\section{REFERENCES}

1. Dattaraya Parle, Dhairyasheel Desai, Ankita Bansal. Estimation of Individual Bite Force during Normal Occlusion using FEA.Altair Technology Conference $2013: 1$-9.

2. Swift EG. Pulpal effect on composite resin restoration. Oper Dent 1989;14:20-7

3. Sensi LG, Strassler HE, Webley W. Direct composite resins. Inside Dentistry.2007; 3(7):
76-81.

4. Xie D, Brantley WA, Culbertson BM, Wang G. Mechanical Properties and

Microstructures of GIC. Dent Mater.2000; 16(2): 129-38.

5. Sharan bir K.Sidhu: Clinical evaluation of resinmodified glass-ionomer restoratios. Journal Dentar 2010:26; 7-12.

6. Mjor Ivar A, Moorhead JE, Dahl JE. Reasons for replacement of restorations in permanent teeth in general dental practice. International Dental Journal. 2000;50: 361-366.

7. Chrysanthakopoulos NA. Placement, replacement and longevity of composite resinbased restorations in permanent teeth in Greece. International Dental Journal.2012; 62:161-166.

8. Soares AC, Cavalheiro A. A review of amalgam and composite longevity for posterior restorations. International dental journal. 2010; 51(3):155-164.

9. Flávio F. Demarco, Marcos B. Corrêaa, Maximiliano S. Cenci, Rafael R. Moraes, and Niek J.M. Longevity of posterior composite restorations: Not only a matter of materials. Dental material 2012; 28:87-101.

10. Espelid I, Cairns J, Askildsen JE, Q Vist V, Garden T, Tveit AB. Preferences over dental restorative materials among young patients and dental professionals . Eur J Oral Sci 2006; 114:15-21.

11. Tarek H.Rabi. Placement of Posterior Composite Restorations in Palestine Dental Practices: Techniques, Problems, and Attitudes. International Journal of Dental Sciences and Research 2015; 3(3): 72-78.

12. Abdul Azim Asy Abdul Aziz, Aimi Amalina Ahmad, Azlan Jaafar, Aws H Ali Al-kadhim, Norazlina Mohammad. Difficulties encountered in materials placement for deep cavity of posterior restoration among dental practices.

Contemporary issue: Islam \& science. Penerbit Usim press 2018: 269-276.

13. Hickel, Reinhard; Manhart, Juergen. Longevity of Restorations in Posterior Teeth and Reasons for Failure. Journal of adhesive dentistry 2001; 3 (1): 45-64.

14. Fariha Naz, Soima Razzaq, M.Rofique, Usman Tariq. Trends for choosing composites for posterior restorations by the dentists in Lahore. Pakistan Oral and Dental Journal 2012; 32:50813. 
15. World Health Organization. Formulating Oral Health Strategy for South-East Asia. Report of regional consultation, Chiang Mai, Thailand, October 2008. New Delhi;WHO SEARO,2009.

16. Kunzemann, K.H. Glass-ionomer cements, hybrid glass-ionomers and compomerslaboratory trials-wear resistance. Trans Acad. Dent. Mater.1996; 9:89-104.

17. FJT Burke, S McHugh, RC Randall, E Widstorm, H Forss, AC Hall. Amalgam and composite use in UK general dental practice in 2001.British Dental Journal 2003;194:613-618.

18. Gilmour AS, Latif M, Addy LD, Lynch CD. Placement of posterior composite restorations in United Kingdom dental practices: techniques, problems, and attitudes. International Dental Journal 2009;59: 148-154.

19. Tran LA, Messer LB. Clinicians choices of restorative materials for children. Australian dental journal 2003;48(4):221-232. 